УДК: 159.923:316.6

DOI $10.21661 / \mathrm{r}-119541$

\title{
А.А. Исаханова
}

\section{ИССЛЕДОВАНИЕ НРАВСТВЕННЫХ ЦЕННОСТЕЙ У ЛЮДЕЙ, ВЕДУЩИХ БРОДЯЖНИЧЕСКИЙ ОБРАЗ ЖИЗНИ В ГОРОДЕ АСТАНА}

Аннотация: бродяжничество в современном мире приобрело масштабный характер. Все больше людей начинают вести бродяжнический образ жизни, уходя от социальной реальности, не справляясь с натиском глобализации и экономической нестабильности. Проблема бродяжничества рассматривается многими авторами, но от этого не становится менее актуальной. В данной статье рассматривается психологическое самоощущение благополучия личности людей, ведущих бродячий образ жизни, через самооценку нравственных показателей, а также затрагивается взаимосвязь психологического благополучия и нравственности личности. Нравственность личности и психологическое благополучие отражают нравственную ориентацию, как отдельной группь, так и государства в целом. Положительные ценностные ориентации и психологическое благополучие как субъективное мироощущение для многонащионального Казахстана являются основой в созидании благополучия и стабильности. Проявления нравственности у людей, ведущих бродяжнический образ жизни, отражает сферу сочиального развития общества на уровне уязвимого социального положения, которое в своём развитии может стать причиной деградаџии общеественного сознания. По этой причине важно отслеживать уровень нравственности многоначионального общества не только в общих представлениях общества в целом, но и у отдельных категорий граждан.

Ключевые слова: личность, нравственные ценности, нравственность, $n с и$ хологическое благополучие, бродяжничество.

\section{A.A. Issakhanova}

\section{THE STUDY OF VAGRANTS' MORAL VALUES IN ASTANA}


Abstract: vagrancy in the modern world has become greater than ever. More and more people become vagrants. They move away from the social reality, can't cope with the onslaught of globalization and economic instability. Vagrancy problem is considered by many authors, but it does not become less relevant. This article discusses the psychological sense of self well-being of vagrants through moral self-esteem indicators. It also describes the relationship of psychological well-being and personal morality. Personal morality and psychological well-being reflect moral orientation of both separate group or the whole country. Positive values and psychological well-being as a subjective attitude for multinational Kazakhstan are the base in prosperity and stability. Vagrants' morality manifestations reflect the social development of society at the level of vulnerable social situation, and its development can cause degradation of public consciousness. For this reason, it is important to monitor the level of morality of a multinational society not only in society's views, but also in certain categories of citizens.

Keywords: person, moral values, moral, psychological well-being, vagrancy.

В XXI веке перед человечеством особо остро встали проблемы социальной направленности, свидетельствующие о тенденции наступления кризисных явлений личностного развития, а так же социальной адаптации в мире глобальных перемен и неустойчивого развития, которые ставят под угрозу всю культурноисторическую систему общечеловеческого развития и существования.

Особое беспокойство у мирового сообщества вызывают экономические и экологические ситуации, неравномерность роста народонаселения на планете, нарастающее увеличение нищеты, безработицы, болезней, и нарушения в генофонде приводят к скрытой проблеме деградации нравственности современной личности.

Нравственность - это показатель нравственного сознания личности. Нравственное сознания основывается на знании о должном, об идеале и о смысле жизни. По этой причине изучение нравственности относят к изучению высших 
психологических образований личности человека, в которых содержится суть бытия человека и высшие ориентации развития личностных качеств.

Основой нравственного сознания являются нравственные ценности, в которых заложено стремление к росту, к самоактуализации как важнейшие качество личности. Актуальная потребность в саморазвитии, стремление к самосовершенствованию являются показателем личностной зрелости и одновременно условием достижения личностной целостности. Ценности являются ориентиром в жизни человека, выступают как механизм социального контроля и воплощаются в поведении. Реализация ценностей на разных возрастных этапах позволяет наслаждаться ощущением удовольствия, счастья.

Проблема ценностных ориентаций в зрелом возрасте является наиболее актуальной, так как связана не только с личностным развитием взрослого человека, но и с преодолением кризисных периодов. Именно в период взрослости наиболее остро происходит осознание и переосмысление личностных ценностей [1].

Понятие взрослой (зрелой) личности - сравнительно новое приобретение психологии развития, во многом обязанное своему употреблению философскому анализу таких явлений, как массовый человек (Х. Ортега-и-Гассет), бегство от свободы, социальный и индивидуальный характер (Э. Фромм), экзистенциальный вакуум, смысл жизни (В. Франкл) и др. Психологическое определение понятия взрослости обнаруживает свою не тождественность понятиям социальной или юридической зрелости, а также сталкивается с трудностями в определении нормы развития в связи с действием культурных факторов и общей инфантилизацией современного населения [2].

Таким образом, по общему предположению и психологическим теориям личности в период зрелости, после переоценки ценностей, происходит расцвет деятельности за счет углубления ее качества. Характерными свойствами личности в этом периоде являются повышенное внимание к процессу самореализации, как в профессиональном, так и в личном плане. Смысл жизни, внимание к здоровью, стремление к стабильности так же характеризуют данный возрастной период. Но, несмотря на все положительные показатели в исследованиях зрелости, 
данный период так же характеризуются потерей ценностных ориентаций и стремительной деградацией личности. Показателем деградации в зрелом возрасте является бродяжничество, избегание стремлений стабильной социализации и развитию. Бродяжничество является актуальной социально-психологической проблемой, т.к. бродяги представляют собой асоциальный тип личности, потерявший жизненные ориентиры нравственного взаимодействия с окружающей средой, способный к непредсказуемым поступкам.

Бродяжничество - это социальное явление, характеризующееся скитанием лиц без определенного места жительства в течение длительного времени по территории страны либо в пределах населенного пункта или города. Бродяжничество обусловлено - отсутствием постоянного жилья у отдельных индивидов или целых семей, что делает невозможным ведение оседлого образа жизни и полноценного социального функционирования. Термин бродяжничество берет свое начало от слова «бродяга» - обнищавший, бездомный человек, скитающийся без определенных занятий, имеющий проблемы с социализацией в обществе его пребывания или проживания [3].

Анализ феномена бродяжничества, в контексте историко-культурного, философского и социально-психологического подходов, позволил выявить множественные разночтения в феноменологическом понимании описываемого явления.

А.О. Лиходей рассматривает бродяжничество как «образ жизни, который складывается в результате разрыва социальных связей» [4]. В.Н. Кудрявцев дает похожее определение: «бродяжничество - систематическое перемещение лица, существующего на нетрудовые доходы, не имеющего постоянного места жительства перемещающийся из одной местности в другую или в пределах одной местности» [5].

В то же время С.Дж. Рибтон-Тарнер в книге «История бродяг и бродяжничества» пишет, что наличие либо отсутствие жилья не является обязательным условием для отнесения индивидуума к сообществу бродяг [6]. 
Бродяжничество довольно универсальный феномен, имеющий отчетливые исторические, философские и культурные корни. Но в настоящее время бродяжничество больше проявляется как психологическая проблема, а возможно и психиатрическая, часто связанная с социально-экономическим развитием мира и нравственными аспектами взаимодействия. Субъективные причины обусловлены психологическими особенностями личности, жизненными установками, микросоциальной ситуацией. В зависимости от субъективных причин можно выделить следующие группы бродяг:

1) люди, для которых бродяжничество является формой уклонения от уголовной ответственности;

2) граждане, принципиально не желающие работать (это наиболее многочисленная группа);

3) лица, обладающие завышенными требованиями к средствам существования, которым не хватает любого заработка;

4) люди, ставшие бродягами вследствие неурядиц в семье или на работе;

5) жертвы социальной пропаганды и собственной романтики;

6) люди с отклонениями в психике [7].

Очень часто ряды бездомных пополняют бывшие заключенные, убегающие от родителей дети, инвалиды, наркоманы и алкоголики, беженцы, военнослужащие, возвращающиеся из других стран. Большинство бездомных - одинокие мужчины. В среднем их возраст от тридцати до пятидесяти, что соответствует показателем зрелого возраста [6].

Проблема бродяжничества затронула все страны мира. Особо остро данная проблема проявляется в развивающихся странах, в число которых входит и Казахстан. Бродяжничество в период экономического кризиса и глобально ориентированного стихийного развития, становится не просто социальной проблемой нарушения во взаимодействии отдельных личностей с обществом, а показателем - деградации нравственных ценностей и ориентаций общества. Следует согласиться с В. А. Ядовым в том, что ценностные ориентации в структуре личности «позволяют уловить наиболее общие социальные детерминанты мотивации 
поведения, истоки которой следует искать в социально-экономической природе общества, его морали, идеологии, культуре, в особенностях социально-группового сознания той среды, в которой формировалась социальная индивидуальность и где протекает повседневная деятельность человека» [7].

В структуре ценностных ориентаций важное место принадлежит поведенческому элементу. При этом следует подчеркнуть, что поведенческий элемент представляет собой «практическое выражение» ценностных ориентаций. Именно поведенческий элемент проявляет нравственную направленность личности, «обнажая» всю вертикаль нравственных ценностей человека в межличностных взаимоотношениях. Ценностные ориентации лежат в основе выбора жизненных целей человека, они объясняют причины его поведения. Их характер и содержание определяют общую направленность личности, которая, в свою очередь, обусловливает нравственную активность человека [8].

Поведенческий элемент бродяг в межличностном взаимодействии социального окружения сопровождается противоречивым отношением общества, вызывая отвращение и не понимание, жалость и сочувствие, как к личностной позиции, так и к поведенческим элементам в целом. Вместе с тем люди, ведущие бродяжнический образ жизни, становятся главными героями полицейской хроники, выступая в качестве участников мелких правонарушений и яркими представителями уголовных дел.

Только по городу Астана официально зарегистрировано более 1300 людей занимающихся бродяжничеством [9]. Однако на настоящий момент, нет надежных источников информации, так как число лиц неустойчиво. Как правило, люди, оказавшиеся на улице, находятся в трудной жизненной ситуации, обусловленной многими факторами, и очень часто выбраться из данного состояния тяжело.

Учитывая все факторы бродяжничества, целью нашего исследования стало выявление соотношения проявления нравственных ценностей в психологическом благополучии личности бродяг зрелого возраста. 
Гипотезой выступило предположение о том, что бродяжнический образ жизни человека приводит к деградация нравственных ценностей, проявляясь в негативном самоощущении психологического благополучия.

В связи со всеми выше изложенными фактами и предположениями, рассмотрение нравственных ценностей и психологического благополучия в современном полиэтничном Казахстане, молодой и развивающейся стране особо актуально. А так как столица страны для каждого государства в мире является особым показателем социального благополучия, данное исследование было проведено в городе Астана.

Задачи данного исследования включили в себя следующие пункты:

- выявление людей, ведущих бродяжнический образ жизни;

- социальная и психологическая помощи в социальной адаптации и социализации людям, ведущим бродяжнический образ жизни;

- определение уровня психологического благополучия личностей, ведущих бродяжнический образ жизни;

- выявление актуальных нравственных ценностей в социальном взаимодействии межличностного характера у людей, ведущих бродяжнический образ жизни между собой, а также с социально благополучными представителями.

В качестве методологического инструмента были использованы:

1. Шкала психологического благополучия К. Рифф [10]. Согласно методике, в структуру психологического благополучия включены такие компоненты, как автономность, компетентность, личностный рост, позитивные отношения, жизненные цели и самопринятие.

2. Опрос, состоящий 25 вопросов, для выявления психологических и социологических причин бродяжничества, нравственности в поведенческих проявлениях.

3. Исследование нравственной самооценки субъекта (Дембо - Рубинштейн). Для исследования были выбраны такие ценности как: любовь к людям, вера, дружба, справедливость, честность, патриотизм, доброжелательность. 
4. Независимое наблюдение и оценка наблюдателей бродяг по методике нравственной самооценки субъекта (Дембо - Рубинштейн).

Общая выборка исследования составила 57 человек (50 мужчин и 7 женщин), возрастной интервал - от 30 до 50 лет.

Стоит сразу же отметить, что респонденты нашего исследования очень тяжело шли на контакт, не желали отвечать на многие вопросы, с первого раза, проявляли агрессивность, или пытались вызвать жалость.

На первом этапе исследования был проведен опрос 150 человек, ведущий по нашим предположениям бродяжнический образ жизни. По полученным результатам опроса были определены 57 человек ведущие бродяжнический образ жизни более двух лет, не желающие прибегать к помощи социальных работников и общественных организаций, для восстановления социальной позиции в обществе или возращение к общепринятому образу жизни. Остальные опрошенные только начали вести бродяжнический образ жизни, или периодически прибегают к нему в силу разнообразных социальных причин, все они обратились, по собственному желанию, в социальные службы города Астана для устранения причин ведущих к бродяжническому образу жизни.

На втором этапе, нами анализировался уровень выраженности различных компонентов психологического благополучия личности (рис. 1) по шкалам: положительные отношения с другими; автономия; управление окружением; личностный рост; цель в жизни; самопринятие.

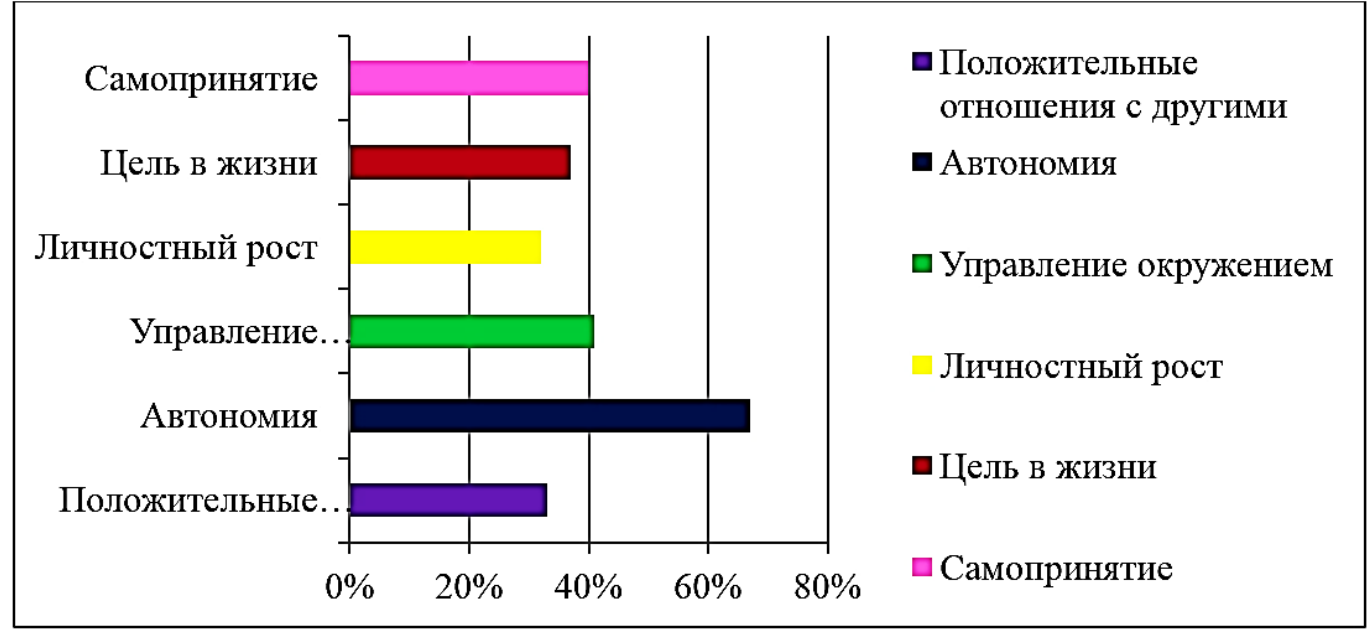

Рис. 1. Уровень психологического благополучия 
Полученные данные по методике К. Риффа «Шкала психологического благополучия» проявили низкие результаты респондентов, что в свою очередь свидетельствует о низкой степени выраженности основных показателей психологического благополучия личности. Так по шкале «Положительные отношения с другими» респонденты, набрали 33\%. Которые свидетельствуют об ограниченном количестве доверительных отношений с окружающими, им сложно быть открытыми, проявлять теплоту и заботиться о других; в межличностных взаимоотношениях, как правило, они изолированы и фрустрированы; не желают идти на компромиссы.

Показатели шкалы «Автономия» составили 67\%. Высокий показатель по данной шкале характеризует респондентов как самостоятельных и независимых, способных противостоять попыткам общества заставить думать и действовать определенным образом.

Шкала «Управление окружением»-41\%. Характеризует респондентов как людей испытывающих сложности в организации повседневной деятельности, они неспособны изменить или улучшить складывающиеся обстоятельства, безрассудно относится к представляющимся возможностям, лишены чувства контроля над происходящим вокруг.

Шкала «Личностный рост» - 32\%. Респонденты осознают отсутствие собственного развития, но не испытывают чувства улучшения или самореализации, испытывают скуку и не имеют интереса к жизни, ощущают неспособность устанавливать новые отношения или изменить свое поведение.

Шкала «Цель жизни»-37\%. Лишены смысла в жизни; имеют мало целей или намерений, в некоторых случаях цели и намерения респондентов ограничиваются лишь удовлетворением своих биологических потребностей; отсутствует чувство направленности, не находят цели в своей прошлой жизни, лишь малая часть респондентов ведущих бродяжнический образ жизни довольна своим прошлым, тепло вспоминает о событиях прошлого и охотна ими делится, остальная 
часть это люди которые с детства были подвержены социальному, педагогическому и психологическому давлению окружающих; не имеют смысла жизни.

Шкала «Самопринятие» - 40\%. Не довольны собой, разочарованы событиями своего прошлого, испытывают беспокойство по поводу некоторых личных качеств, желают быть не тем, кем он или она являются. Самопринятие очень сложно в их положение большинство респондентов плохо осознает в каком плачевном социальном и экономическом положении они находятся, они ждут большего от общества и часто говорят о том что их не оцени в обществе, не увидели всего потенциала на который они способны и не помогли всем их способностям проявится, респонденты винят свое окружение и не принимают, не осознают свое состояние.

Следующий шаг второго этапа исследования включал методику исследование нравственной самооценки субъекта Дембо-Рубинштейн. Методика ДембоРубинштейн позволяет определить самооценку личности. Это происходит с помощью отметок испытуемого на определенных шкалах. Респондентам был предложен бланк методики со шкалами, каждая из которых была 10 см., соответственно отметки выверялись по 10 бальной шкале. Шкалы методики включали общечеловеческие ценности, которые нужно было оценить. По шкале честность - были получены самые высокие результаты по данной методике, доброжелательность, любовь к людям, справедливость - на втором месте, по шкалам вера, дружба - результаты низкие, и наименьшие результаты были выявлены по шкале патриотизм, в среднем показатели патриотизма в самооценке респондентов близки к нулю. 


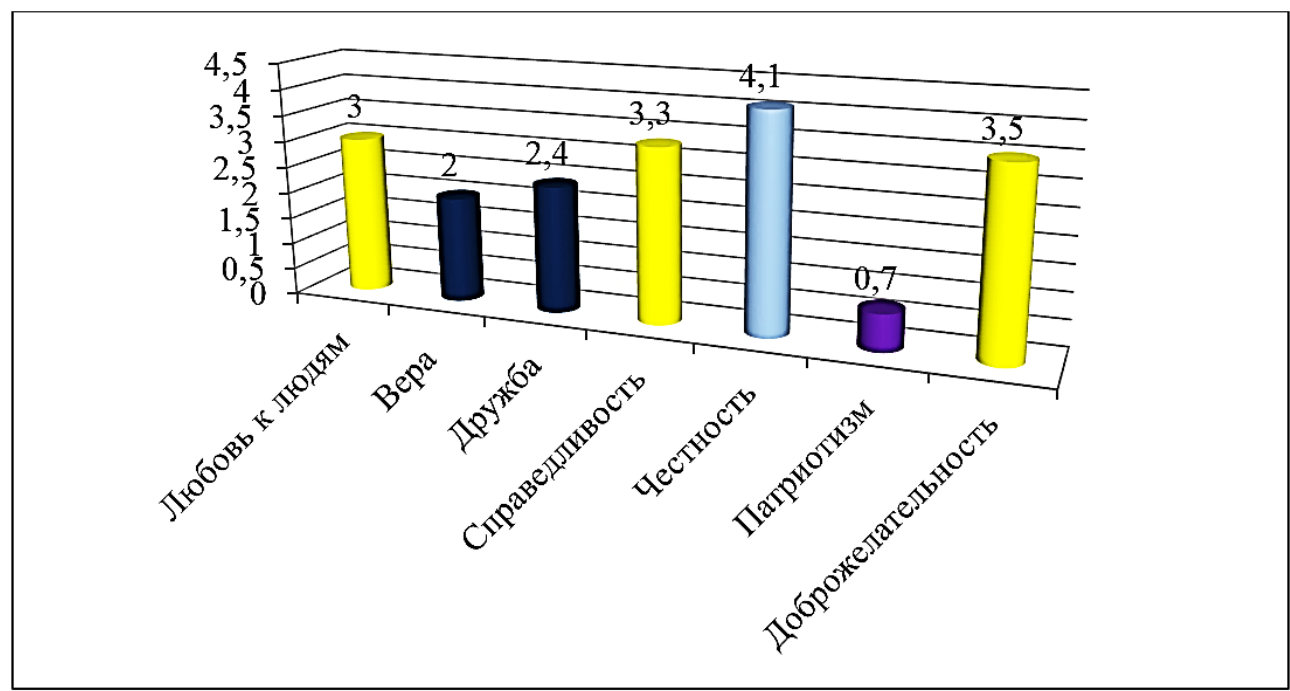

Рис. 2. Показатели по методике исследование нравственной самооценки

По методике исследование нравственной самооценки у наших респондентов все показатели довольно низкие. Самый низкий показатель по шкале патриотизм составил - 0,7 балла, результаты данной методике соответствуют полученным результатам по методике исследования «Шкала психологического благополучия К. Рифф». В силу, антисоциального образа жизни и психологических трудностей, в процессе исследования самооценка респондентов могла быть занижена, в связи с чем, полученные данные по двум методикам очень низкие.

Третий этап нашего исследования состоял в независимом наблюдении за респондентами в условиях их повседневного проживания и оценка их нравственных ценностей независимыми исследователями, ориентированными на изучение социальных и психологических особенностей взаимодействия личности в социальной среде.

Наблюдение за респондентами ведущими бродяжнический образ жизни велось в течении одной недели тремя независимыми исследователями, которые в дальнейшем оценивали нравственные ценности респондентов по методике исследование нравственной самооценки субъекта Дембо-Рубинштейн. 


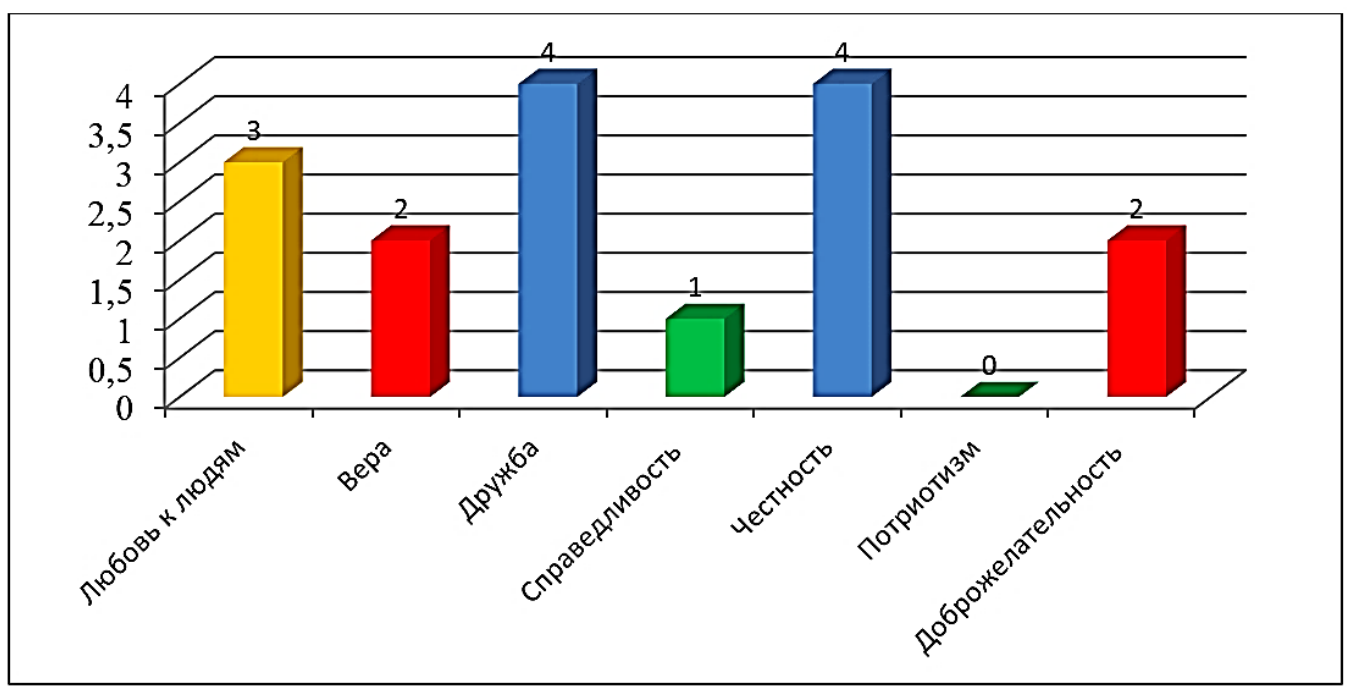

Рис. 3. Показатели по методике исследование нравственной самооценки

Данные полученные в процессе проведения независимого наблюдения в изучении проблемы нравственности, приглашенными исследователями, разнятся с результатами исследования респондентов по нескольким показателям. При сравнении результатов по методике самооценки нравственных ценностей личности отличия наблюдаются по шкале дружба на 1,6 балла, по оценке независимых наблюдателей дружба у респондентов проявляется выше их самооценки. А, вот по шкале справедливость результаты противоположные по самооценке респондентов если они составляют в среднем 3,3 балла, то по оценке наблюдателей - 1 балл. Стоит отметить, что по шкалам любовь к людям, вера, честность, патриотизм баллы в обоих случаях практически одинаковые, а разница между показателями незначительная и в среднем близка к нулю.

Полученные результаты исследования нравственных ценностей и психологического благополучия личности бродяг зрелого возраста по городу Астана, выявили низкие показатели. Саморазвитие и самоактуализация личности у респондентов данного исследования на очень низком уровне, что влечет за собой последствия низкого психологического благополучия. Вместе с тем, если опираться на теорию психологического благополучия К. Рифф [11], разработанную в рамках гуманистического подхода, структура психологического благополучия рассматривается как совокупность различных аспектов позитивного психологи- 
ческого функционирования личности. Позитивное психологическое функционирование личности состоит из нескольких компонентов высокую автономию, личностный рост, управление окружающей средой, позитивные отношения с другими людьми, наличие жизненных целей и позитивную оценку себя. Нравственные ценности, непосредственно, не являются составляющей частью позитивного психологического функционирования. Но нравственность оказывает влияние на принятие человека самого себя таким, каков он есть, что является ожидаемым результатом, поскольку человек, мыслящий и ведущий себя по отношению к другим нравственно, вполне обоснованно относится к себе и своим личностным качествам положительно. Ощущение психологического благополучия не связано с такой составляющей нравственности, как ориентация на добро, однако зависит от другого её компонента - ориентации на зло. Чем сильнее в своих мыслях и поступках человек ориентирован на зло, тем он более негативно оценивает самого себя и считает себя зависимым человеком, что приводит его к ощущению психологического неблагополучия [12].

Наше исследование психологического благополучия через самооценку нравственных ценностей людей среднего возраста, ведущих бродяжнических образ жизни стало подтверждением того что деградация нравственных ценностей влияет на самоощущение личности, чем ниже показатели нравственности, тем ниже уровень счастья и удовлетворенности своей жизнью.

Феномен психологического благополучия является субъективным ощущением благополучия личности, отражая мироощущение человека, состоящего по предположению К. Рифф, из шести факторов оценки благополучия. Но вместе с тем, в процессе исследования нами было отмечено, что нравственность личности в процессе взаимоотношений с социальной средой, так же играет важную роль в психологическом благополучии, и неразрывно связанно с самовосприятием и позитивным самоощущением. Нравственность оказывает влияние на самовосприятие личности в условиях взаимодействия с социальной средой, которая в свою очередь структурирована этническими, психологическими, личностными и об- 
щечеловеческими ценностями. Ценности среды в процессе социализации личности становятся общепринятыми нравственными ценностями, в равной степени соблюдаемые всеми членами социальной среды, не соблюдение же ценностей приводит к осуждению отдельных личностей обществом, и приводит к отторжению их в социальном взаимодействии. В ходе многочисленных исследований именно социальное отторжение общества отдельных личностей приводит их разрушению самовосприятия и самосознания.

В заключении можно сказать, исходя из всех вышеприведенных данных, люди без определенного места жительства - это проблема, не только социального характера но и психологического ведущая к деградации личности во всех ее направлениях. Негативное мироощущение, самоощущение и психологическое благополучие ведет к саморазрушению личности и всего его пространства. Личность, не имеющая положительного самоощущения, не может иметь в своем социальном пространстве счастливых и независимых людей, все кто окружают человека в процессе личностного саморазрушения, становятся участниками этого процесса, и вместе с тем могут запустить данный процесс и в своем бытие.

\section{Сиисок литературы}

1. Ихсанова Д.Т. Социально-психологические особенности ценностных ориентаций в зрелом возрасте // Вестник КазНУ. Серия психологии и социологии. - 2014. - №3 (50). - С. 59-68.

2. Аскарова Р.К. Психологический анализ феномена «психологическое благополучие» (по материалам литературного обзора) // Вестник КазНУ. Серия психологии и социологии. - 2016. - №4 (59). - С. 27-32.

3. Беляев С.А. Психосоциальные аспекты бродяжничества // Психосоциальная адаптация в трансформирующимся обществе: проблемы и перспективы: Материалы II Международной научной конференции, г. Минск, 26 октября 2007 г. / Ред. кол. И.А. Фурманов [и др.] - Минск: Изд-во Издательский центр БГУ, 2007. - C. 131-138.

4. Лиходей О.А. Субъективные факторы маргинализации. - М.: ЮПресс, 2001. $-231 \mathrm{c}$. 
5. В.Н. Кудрявцев Социальные отклонения. - М.: Юридическая литература, 1989. $-258 \mathrm{c}$.

6. C.J. Ribton-Turner The History of Vagrants and Vagrancy. - Columbia: Columbia Encuclopedia, 2008. - 312 c.

7. Причины бродяжничества [Электронный ресурс]. - Режим доступа: http://www.studfiles.ru/preview/2377244/page:5/

8. Антилогова Л.Н. О взаимосвязи ценностных ориентаций и нравственной активности личности [Электронный ресурс]. - Режим доступа: http://hpsy.ru/public/x2629.htm

9. Астанада кәмелетке толмаған қаңғыбас балалар [Электронный ресурс]. Режим доступа: http://www.azattyq.org/a/1160229.html

10. Жуковская Л.В. Шкала психологического благополучия К. Рифф / Л.В. Жуковская, Е.Г. Трошихина // Психологический журнал. - 2011. - Т. 32. №2. - C. 82-93.

11. C.D. Ryff Happiness is everything, or is it? Explorations on the meaning of psychological well-being // Journal of Personality and Social Psychology. - 1989. Vol. 57. - P. 1069-1081.

12. Бескова Т.В. Соотношение психологического благополучия с нравственностью и религиозностью личности // Вестник Московского государственного областного университета (электронный журнал). - 2015. - №4 [Электронный pecypc]. - Режим доступа: www.evestnik-mgou.ru (дата обращения: 10.02.2017).

Исаханова Асель Алимахановна - доктор философии (PhD), старший преподаватель кафедры социологии Евразийского национального университета им. Л.Н. Гумилева, Республика Казахстан, Астана.

Issakhanova Assel Alimakhanovna - doctor of philosophy $(\mathrm{PhD})$, senior lecturer of Sociology Department at the L.N. Gumilyov Eurasian National University, the Republic of Kazakhstan, Astana. 